\title{
Historia de la Educación y Literatura. Miradas cruzadas para comprender la experiencia escolar*
}

Pablo Pineau

Profesor titular regular de la cátedra de Historia de la Educación Argentina y Latinoamericana de la Universidad de Buenos Aires (Argentina). Correo electrónico: pablopineau@gmail.com.ar. El autor es doctor en Educación de la Universidad de Buenos Aires (Argentina). Entre sus publicaciones recientes tenemos: "Historiografía educativa sobre estéticas y sensibilidades en América Latina: un balance (que se sabe) incompleto". Revista Brasileira de História da Educação Vol. 18 No. 48 (2018). Entre sus temas de interés están Historia de la educación.

Recibido: 24 de abril de 2017

Aprobado: 20 de diciembre de 2017

Modificado: 12 de abril de 2018

Artículo de investigación científica

DOI: http://dx.doi.org/10.15648/hc.33.2018.7

* $\quad$ Este artículo forma parte del proyecto: "Historia de la Educación y Literatura", financiación propia. Esta publicación está bajo una licencia Creative Commons Reconocimiento-NoComercial 4.0 
Historia de la Educación y Literatura. Miradas cruzadas para comprender la experiencia escolar

Este artículo indaga en los cruces entre Historia de la Educación y Literatura para analizar la experiencia escolar en una búsqueda de superar los límites de abordajes tradicionales. Focaliza en un conjunto de novelas de formación, memorias de estudiantes y memorias de profesores en los cuales distintos escritores consagrados, docentes y alumnos latinoamericanos y especialmente argentinos relatan experiencias escolares ficticias o verdaderas.

En todos ellos, el lugar donde se lleva a cabo el proceso educativo no aparece como una entidad aislada de la sociedad, sino como su símbolo. Las instituciones educativas son presentadas como uno de los espacios centrales donde se desarrollaron las experiencias de vida que tallaron el destino y la identidad de sus protagonistas.

Palabras clave: literatura, experiencia escolar, novela de formación, memorias de estudiantes, memorias de docentes.

History of Education and Literature. Diverse perspective to understand the school experience

This paper explores the History of Education and Literature to analyze the school experience beyond the limitations of traditional approaches. It focuses on a set of novels of formation, students and teachers' memoires in which different recognized writers, teachers and students from Latin America, and especially from Argentina, report fictitious or reliable school experiences.

In all of them, the place where the educational process takes place does not appear as an isolated entity of society, but as a symbol. The educational institutions are presented as one of the key spaces where life experiences that carved the destiny and identity of its protagonists were developed.

Key words: literature, school experience, bildungsroman (novel of formation), students' memoires, teachers' memoires. 


\section{História da Educação e Literatura. Miradas cruzadas para compreender a expe- riência escolar}

\section{Resumo}

Este artigo indaga nos cruzes entre História da Educação e Literatura para analisar a experiência escolar numa busca de superar os limites de abordagens tradicionais. Focaliza num conjunto de novelas de formação, memórias de estudantes e memórias de professores em os quais diferentes escritores consagrados, professores e alunos latinoamericanos e especialmente argentinos relatam experiências escoares fictícias ou verdadeiras.

Em todos eles, o lugar onde leva-se a cabo o processo educativo não aparece como uma entidade isolada da sociedade, sina como seu símbolo. As instituições educativas são apresentadas como um dos espaços centrais onde se desenvolveram as experiências de vida que talharam o destino e a identidade de seus protagonistas.

Palavras-chave: literatura, experiência escolar, novela de formação, memórias de estudantes, memórias de professores.

\section{Histoire de l'Éducation et la Littérature. Regards croisés pour comprendre l'ex- périence scolaire}

Cet article mène une enquête sur les croisements entre l'Histoire de l'Éducation et la Littérature, afin d'analyser l'expérience scolaire dans la recherche pour dépasser les limites d' abordage traditionnelles. Il focalise dans un ensemble de romans de formation, mémoires d'étudiants et mémoires de professeurs entre lesquels plusieurs écrivains de renommé, enseignants et étudiants latino-américains et spécialement argentins, relatent des expériences scolaires fictives ou réelles.

Dans tous, le lieu où se réalise le processus éducatif n’apparait pas comme une entité isolée de la société mais comme son symbole. Les institutions éducatives sont présentées comme un des espaces centraux ou se sont déroulé les expériences de vie qu’ont taillée le destin et l'identité de leurs protagonistes.

Mots clés: littérature, expérience scolaire, roman de formation, mémoires d'étudiants, mémoires d'enseignants. 


\section{INTRODUCCIÓN}

"Reflexioné que todas las cosas le suceden a uno precisamente, precisamente ahora. Siglos de siglos y solo en el presente ocurren los hechos: innumerables hombres en el aire, en la tierra y en el mar, y todo lo que realmente pasa me pasa a mí..." Jorge Luis Borges, El jardín de los senderos que se bifurcan ${ }^{1}$

En los últimos años, la producción académica fue abandonando una historia de la educación que construye como su objeto, en forma exclusiva y discreta, temas como las ideas pedagógicas, las instituciones educativas, la legislación al respecto, o la biografía de ciertos sujetos «ilustres», para dar lugar a una historia de la educación más «social» y "cultural” que busca dar cuenta de lo educativo como campo de debates y producciones mediante su inscripción en relatos mayores. Al respecto, Agustín Escolano Benito ${ }^{2}$ sostiene que en los últimos años la historiografía educativa se ha vuelto más antropológica y etnográfica, y menos racionalista e "ideológica". De esta forma, ha consolidado nuevos objetos de estudio, entre los que queremos destacar aquí aquellos que se refieren a los saberes y prácticas vinculados al mundo de las emociones y los sentimientos, a la generación de las percepciones estéticas, y a la reconstrucción de las vivencias de los sujetos intervinientes. En términos metodológicos, esto ha implicado sumar al análisis una serie de fuentes no tradicionales para pensar los fenómenos educativos y escolares, entre los que se encuentran la cultura material, los libros de textos, los cuadernos de clase, los representaciones icónicas, los medios de comunicación masiva y, en en el caso que nos interesa en este escrito, la literatura.

En todos estos movimientos y cruces, la "experiencia escolar" se ha tornado un interesante objeto de análisis para nuestro campo de indagación. Pero, ¿de qué se habla cuando se habla de "experiencia”? Según parece

1561 Jorge Luis Borges, "El jardín de los senderos que se bifurcan”, en Obras completas, Jorge Luis Borges, (Buenos Aires: MC Editores, 1974), 475.

2 Agustín Escolano Benito, "Reseña del libro: Stuart Walton, Humanidad. Una historia de las emociones", Historia y Memoria de la Educación, Vol. 2 (2015). 
hace referencia a deducirse de la cita de Borges con la que se inicia este artículo, es un "a mí y aquí", es algo irrepetible, inasible, idiosincrásico y fugaz. Es un "acontecer en uno", un suceder que hace tajos, produce efectos, indica caminos y desvíos, deja marcas, conforma o modifica destinos. La historia es el resultado de lo que (nos) hicieron -y supimos hacer connuestras experiencias ${ }^{3}$.

El peso de su impronta convoca a intentar recuperarla, frenarla y revisitarla, y una de las mejores formas de hacerlo es la narración. Narrar un hecho es tratar de volver a él, reinstalarse en las sensaciones que produjo, iluminar algunas nuevas, y clarificar las que quedaron oscuras. Pero, además, narrar es el intento de compartir la experiencia, de ofrecérsela a -y con, y contra, y a pesar de, y junto a, y mediante- los otros, de permitir nuevas miradas que sumen aristas, matices o pliegues. Es ponerlo en la circulación social, en tensar su carácter idiosincrásico para volverla colectiva.

Para nuestro campo de trabajo, una mención especial merecen las formas de narración escritas de la experiencia escolar. En las sociedades modernas "narrar" se tradujo mayoritariamente en "escribir", y "acto educativo" en "escuela". Así, las generaciones pasadas nos han legado muchos escritos en los cuales se propusieron reconstruir su experiencia educativa, fundamentalmente la escolar, tal vez como un homenaje a la institución que los dotó de la poderosa arma de la lectoescritura ${ }^{4}$.

Jaume Trilla $a^{5}$ sostiene que las narraciones pedagógicas tienen dos posibilidades para pensar la educación: su valor didáctico y su valor gnoseológico. Con el primero se refiere a sus potencialidades para "hacer vivir vicariamente la experiencia educativa real del autor. (..) La narración, mucho más que el tratado y el ensayo, genera una suerte de empatía del lector hacia el autor, quien suele ser también el protagonista de la narración”. Con el

3 Jorge Larrosa, "Sobre la experiencia”, Educación y Pedagogía, vol. 18 (2006): 43-51.

4 Martha Isabel Lenero Llaca, "Indicios literarios de la escuela: Aproximaciones a una poética de la memoria", en Lecturas in-apropiadas desde la historia, la educación y la cultura, (coord.) María Esther Aguirre Lora (México: Ediciones Díaz de Santos, 2013), 83-109.

5 Jaume Trilla, "Pedagogías narrativas", en La aborrecida escuela. Junto a una pedagogía de la felicidad y otras cosas, Jaume Trilla (Barcelona: Ed. Laertes, 2002), 136 y ss. 
segundo, su valor gnoseológico, se refiere a que "la narración de lo realizado en forma de experiencia, obliga a un cierto tipo de conceptualización, y, por tanto, de reflexión sobre la experiencia. La escritura narrativa es una forma de rememorización a ritmo lento que posibilita una revisión también pausada de lo realizado. Además, el pensamiento inductivo que es propio del acto narrativo supone atender a algo que es propio de la realidad: el matiz, la diferencia. El matiz que se resiste al concepto y al código pero que, por ello mismo, obliga a repensar los propios conceptos y códigos mediante los que el escritor intentaba rememorar, expresar y reflexionar la experiencia".

En función de estos planteos, en este artículo nos proponemos analizar una selección de narraciones literarias, ficticias o verdaderas, para reconstruir la experiencia escolar. Son producciones de autores diversos - escritores consagrados, alumnos y docentes- de la literatura latinoamericana, con mayor presencia de la argentina ${ }^{6}$, a fin de poder reconstruir y comprender la experiencia escolar.

\section{La "Novela de Formación"}

En la escritura "culta" -la llamada literatura académica-, la temática pedagógica y escolar ha sido abordada por muchos escritores consagrados. Una de sus modalidades destacadas han sido las "novelas de formación, aprendizaje o educación" (Bildungsroman): relatos que se ocupan de la vida de un protagonista sensible que intenta aprender la naturaleza del mundo, descubrir su significado, y adquirir una filosofía de la vida y del arte de vivir. Se originó en la Alemania en el siglo XVIII, ejemplificada con "Los años de aprendizaje de Wilhelm Meister" de Goethe ${ }^{7}$.

6 Cabe aclarar que en un análisis más exhaustivo sobre el tema, se deberían sumar los géneros producidos por la escuela para su propio uso, como los textos escolares, los escritos rituales -himnos, discursos, juramentos- y las composiciones y descripciones. Además, es posible identificar la irrupción de géneros más contemporáneos como las letras de canciones, la literatura infantil y juvenil, y hasta el absurdo y la parodia. También merecen ser investigadas las producciones textuales de formato informático como los blogs.

7 Otros ejemplos son El árbol de la ciencia, de Pío Baroja; La montaña mágica, de Thomas Mann, El cazador oculto, de J. D. Salinger, Las tribulaciones del estudiante Törless, de Robert Musil; Retrato del artista adolescente, de James Joyce; Siddharta y Demian, de Hermann Hesse y El palacio de la luna, de Paul Auster. Para América Latina, "Don Segundo Sombra", de Ricardo Guiraldes, Paradiso de José Lezama Lima, "Río Fugitivo" de Edmundo Paz-Soldán, "Chico Carlo" de Juana de Ibarborou, y "Las Buenas Conciencias" de Carlos Fuentes. 
Este género rompió con la tradición narrativa conocida hasta entonces, al abandonar la centralidad de describir acontecimientos externos a los sujetos -como eran las novelas de aventuras y de caballería-, para focalizar en el desarrollo interno del protagonista, mutaciones que se vuelven el punto central del argumento. Su estructura está bien definida, y el tiempo de la narración transcurre generalmente de manera lineal. En algunos casos abarca toda la vida de un hombre; en muchos focaliza en su adolescencia y juventud, y ocasionalmente en su adultez y vejez. El interés del relato se dirige a la percepción que el protagonista tiene del mundo que lo rodea, quien en su proceso de aprendizaje debe sacar de su existencia una "lección de vida" y, una vez alcanzada su madurez, debe lograr integrarse a la sociedad. El conflicto se manifiesta en la dialéctica entre los requerimientos sociales y la voluntad de autoformación, en las fricciones entre las condiciones del medio y los ideales de un individuo en un período de formación.

Mijail Bajtin se dedicó al análisis de este género en uno de sus trabajos. Allí sostiene que este tipo de narración:

“...ofrece una imagen del hombre en proceso de desarrollo. En oposición a la unidad estática (de otros géneros), en este tipo de novela se propone una unidad dinámica de la imagen del protagonista. El héroe mismo y su carácter llegan a ser una variable dentro de la fórmula de la novela. La transformación del propio héroe adquiere una importancia para el argumento y en esta relación se reevalúa y se reconstruye todo el argumento de la novela. El tiempo penetra en el interior del hombre, forma parte de su imagen cambiando considerablemente la importancia de todos los momentos de su vida y su destino".

En estas narraciones, las experiencias que le van sucediendo al personaje son lo que lo van cambiando y volviendo otro. Si al empezar el relato es uno, es otro al terminarlo afectado por su desarrollo. O sea, estas narra-

8 Mijail Bajtin, “La novela de educación”, en Estética de la creación verbal, Mijail Bajtin (México: Siglo Veintiuno, 1995), 212. 
ciones son el pasaje de un ser "no educado" a uno "educado". Los cambios producidos se explican como efectos de esas experiencias educativas -muchas veces escolares-, de las formas en que las va incorporando y lo fueron moldeando. Y a su vez, es posible suponer que seguirán fraguando su futuro.

La "novela de formación" se hace cargo de las concepciones educativas modernas, en las cuales los colectivos "infancia" y "juventud" fueron separados del de la "adultez". Los menores fueron comprendidos como seres incompletos, lo que los convirtió en sujetos que debían ser educados en instituciones específicas. Se construyó un sujeto pedagógico, el "alumno”, y se lo volvió sinónimo de infante normal. Educar fue completar al niño o joven para volverlo adulto, en la fricción ya señalada entre la voluntad de autoformación y los condicionamientos sociales.

Detengámonos para este apartado en el caso en el análisis de la novela "La ciudad y los perros" del peruano Mario Vargas Llosa publicada en 1962, cuya trama se centra en la vida de un grupo de alumnos varones del Colegio Militar "Leoncio Prado" de Lima. Allí concurren mayoritariamente los hijos díscolos de las familias pudientes, muchachos "de carácter débill", enviados allí "para que se hagan unos hombres"; y los miembros de familias modestas que apuestan a un ascenso social. El encuentro entre ambos constituye uno de los focos de desarrollo de la obra.

En esa institución, los protagonistas sufren una serie de experiencias asociadas a la construcción de la virilidad y de las jerarquías sociales, que forjan su carácter y lo vuelven "otro". De hecho, cambian sus nombres por apodos que los identifican dentro del grupo de pares tales como 'El Jaguar', 'Cava', 'El Poeta' o 'El Boa'. Son todos “perros”, epíteto despectivo con el que son llamados los cadetes más jóvenes por el resto de los integrantes de la institución.

Veamos el siguiente párrafo:

"Ha olvidado la casa de la avenida Salaberry, en Magdalena Nueva, donde vivió desde la noche en que llegó a Lima por prime- 
ra vez, y el viaje de dieciocho horas en automóvil, el desfile de pueblos en ruinas, los arenales, los valles minúsculos, a ratos el mar, campos de algodón, pueblos y arenales. Iba con el rostro pegado a la ventanilla y sentía su cuerpo roído por la excitación: "Voy a ver Lima". A veces, su madre lo atraía hacia ella, murmurando, "Richi, Ricardo". Él pensaba: “¿Por qué llora?”. (...). Y sintió como, de nuevo, una ansiedad feroz, como tres días antes, cuando su madre, llamándola aparte para que no la oyera la tía Adelina, le dijo: “Tu papÁ no está muerto, es mentira, Acaba de volver de un viaje muy largo y nos espera en Lima".

Luego de una serie de sucesos familiares dolorosos, Ricardo, el protagonista, ingresa al Colegio Militar. El niño de ocho años que dejó su pueblo al enterarse de la existencia de su padre, atraviesa su adolescencia y sus vicisitudes asociadas - por ejemplo, su primer amor- en esa institución. Alí se convierte en El Esclavo, es maltratado como tal y termina encontrando un final trágico. Su carácter se forja en ese devenir entre las condiciones subjetivas y personales, y las sociales y colectivas.

Como es regla en las novelas de formación, el lugar donde se lleva a cabo el proceso educativo -en este caso, la Academia Militar- no aparece como una entidad aislada de la sociedad, sino como su símbolo. Lo que ocurre en un espacio mayor -la ciudad en este caso, como lo indica el nombre de la obra- tiene su resonancia en el otro espacio menor, la institución educativa, y viceversa. La sociedad limeña se refleja, a veces en forma distorsionada, dentro del internado. Sus diferencias, sus humillaciones, sus hipocresías se presentan murallas dentro. El autor fija una mirada desolada en la fuerte jerarquía piramidal que impera en el colegio -microcosmos de Lima, y por extensión de todo el Perú, de Latinoamérica y de la sociedad capitalista-, donde la traición, la violencia, la explotación, el patriarcado y la degradación humana son la garantía para que los estratos altos de la pirámide conserven sus privilegios. Las contradicciones de la sociedad peruana -como los problemas de clase y raza, ya que en el colegio conviven blancos ricos, blancos pobres, cholos, serranos e indios- afloran en la obra para denunciar su corrupción y brutalidad.

9 Mario Vargas Llosa, La ciudad y los perros (Barcelona: Seix Barral, 1963), 15. 
VéaNse al respecto los párrafos con los que se inician la novela, en la que en un pantallazo se presentan las relaciones de los personajes tanto dentro como fuera de la institución, en una imagen que apela a la sordidez de ambos mundos:

“-Cuatro- dijo el Jaguar.

Los rostros de suavizaron en el resplandor vacilante que el globo de luz difundía por el recinto, a través de escasas partículas limpias de vidrio: el peligro había desaparecido para todos, salvo para Porfirio Cava. Los dados estaban quietos, marcaban tres y uno, su blancura contrastaba con el suelo sucio.

—Cuatro— repitió el Jaguar-. ¿Quién?

-Yo-murmuró Cava- Dije cuatro

Apúrate —replicó el Jaguar—. Ya sabes, el segundo de la izquierda.

Cava sintió frío. Los baños estaban al fondo de las cuadras, separados de ellas por una delgada puerta de madera, y no tenían ventanas. En años anteriores, el invierno sólo llegaba al dormitorio de los cadetes, colándose por los vidrios rotos de las rendijas; pero este año era agresivo y casi ningún rincón del colegio se libraba del viento, que, en las noches, conseguía penetrar hasta en los baños, disipar la hediondez acumulada durante el día y destruir su atmósfera tibia. Pero Cava había nacido y vivido en la sierra, estaba acostumbrado al invierno: era el miedo lo que erizaba su piel.

— ¿Se acabó? ¿Puedo irme a dormir? —dijo Boa: un cuerpo y una voz desmesurados, un plumero de pelos grasientos que corona una cabeza prominente, un rostro diminuto de ojos hundidos por el sueño. Tenía la boca abierta, del labio inferior adelantado colgaba una hebra de tabaco. El Jaguar se había vuelto a mirarlo. —Entro de imaginaria a la una - dijo Boa —. Quisiera dormir algo

—Váyanse — dijo el Jaguar —. Los despertaré a las cinco.

Boa y Rulos salieron. Uno de ellos tropezó al cruzar el umbral y maldijo.

Apenas regreses, me despiertas —ordenó el Jaguar- No te demores mucho. Van a ser las doce. 
- Sí — dijo Cava. Su rostro, por lo común impenetrable, parecía fatigado- Voy a vestirme" ${ }^{10}$.

Como en este caso, muchas veces la imagen de las instituciones educativas que este género transmite es bastante negativa. Un fuerte tono de denuncia, que se hizo más evidente en las producciones de la segunda mitad del siglo XX al calor de sus movimientos sociales y culturales, tiñe a estas obras en tonos de una queja que presenta imágenes desagradables, silencios obligados y humillaciones diversas. De esta forma, la experiencia escolar suele ser narrada por los escritores "consagrados" de dicho periodo como frustrante, degradante, aburrida e intelectualmente pobre. Se detienen en describir envejecimientos y obsolencias varias - de mobiliario, programas y docentes-, sufrimientos de los alumnos por abandono, maltrato, crueldad o degradación, aislamientos institucionales y aprendizajes absurdos y mecánicos. En estos casos, la experiencia escolar aparece como un acto de imposición absoluta, omnímoda y omnipotente, sin ningún lugar a un porqué, a una explicación, o a un diálogo.

\section{GÉNEROS ESCOLARES}

A su vez, la escuela también produjo géneros ${ }^{11}$ de escritura más propios, que en la jerarquía literaria académica alcanzaron posiciones menores. Entre ellas se encuentran las "estudiantinas" -obras compuestas por los recuerdos escolares de los alumnos-, y las memorias de docentes. Ambos casos son generalmente obras cortas compuestas por textos breves y anecdóticos, en primera persona, con mucha presencia de un autor que cuenta situaciones de su vida escolar siempre desde el recuerdo, desde alguien que ya ha dejado la condición y la rememora -ya sea su condición de estudiante o docente- para revivirla en tonos mayormente laudatorios, pero que en períodos más actuales -como en el resto de los casos-avanzan los registros de denuncia.

10 Mario Vargas Llosa, La ciudad y los perros, 48.

11 Cabe aclarar que estamos usando esta categoría no en sentido estricto sino amplio para referirnos a agrupamiento de escritos con ciertas características comunes de estilo o contenido. 
Inscribiéndose en las concepciones modernas sobre educación, la escuela es presentada como uno de los espacios centrales donde se desarrollaron las experiencias de vida que tallaron el destino y la identidad del autor. Esto es evaluado frecuentemente en forma muy efectiva. Si positiva, la melancolía y la devoción son tópicos comunes en estas obras; si negativa, en forma de denuncia, burla o parodia.

\subsection{Las estudiantinas}

Pueden ser consideradas un tipo de Bildungsroman generalmente panegíricas limitadas a la experiencia escolar. Para el caso argentino se destaca tempranamente "Juvenilia", de Miguel Cané ${ }^{12}$, escrita originariamente en 1882. El libro fue un éxito en poco tiempo, por lo que fue reeditado por su autor en 1901 sin producirle cambios. En ella él autor reconstruye su paso por el Colegio Nacional de Buenos Aires en la década de 1860, institución recientemente creada por el presidente Bartolomé Mitre como parte de su proyecto de construcción de un Estado Nacional fuerte en consonancia con los intereses de una oligarquía pro-capitalista en ascenso. En esa obra, Cané construyó la versión oficial sobre las experiencias de paso por la escuela media, que perduró por mucho tiempo y fue repetida en muchas obras posteriores.

Josefina Ludmer ${ }^{13}$ sostiene que Juvenilia se ubica en el clivaje en el cual la pelea entre Buenos Aires y el Interior por la construcción de la Nación se desplaza de los campos de batalla militar al debate cultural. Por tal, en la obra, Cané muestra el avance de las ideas seculares y el retroceso de las religiosas, la transición de la cultura hispánica a la francesa como símbolo de distinción, y la formación de una nueva élite letrada más moderna que ocuparía el aparato estatal en breve.

Como en el resto de las Bildungsroman, los cambios externos se inscriben junto con los internos. Las referencias geográficas de la ubicación del Colegio, cerca de los espacios donde se discutía la "política" nacional permi-

16412 Miguel Cané (1851-1905), abogado, profesor universitario, intendente de la ciudad de Buenos Aires, diputado, senador, diplomático y escritor vinculado a la oligarquía terrateniente que dominó el país hacia fines del siglo XIX y comienzos del XX.

13 Josefina Ludmer, El cuerpo del delito. Un manual (Buenos Aires: Perfil, 1999), 78 y ss. 
ten reformar el mecanismo de identificación entre los sucesos internos y externos. Por ejemplo, Cané, en su condición de estudiante, participó en las revueltas de "crudos y cocidos" de $1863^{14}$. Así lo recuerda:

"Como escribo sin plan y a medida que los recuerdos vienen, me detengo en uno que ha quedado presente en mi memoria con una clara persistencia. Me refiero al famoso 22 de abril de 1863, en que "crudos" y "cocidos" estuvieron a punto de ensangrentar la ciudad; los cocidos por la causa que los crudos hicieron triunfar en 1880, y recíprocamente. Yo era crudo y crudo "enragé". Primero porque mis parientes, los Varela, uno de los cuales, Horacio, era como mi hermano mayor, tenían esa opinión, según leía, de tiempo en tiempo, en la tribuna, y en segundo lugar porque la mayor parte de los provincianos eran cocidos. (..).

(E)l rumor de lo que pasaba dentro nos hacía arder por penetrar en el recinto de la Legislatura. ¡Imposible! Entonces de común acuerdo y comprendiendo que era allí donde se desenvolvían las escenas más interesantes, resolvimos reingresar al Colegio y llegar a la Legislatura por las azoteas. Lo hicimos, y a favor del tumulto que entre los claustros se notaba, ganamos el techo y como gatos nos corrimos hasta dominar el patio de la Legislatura. Al primero que vi fue a Horacio Varela, tranquilo, sonriendo y apoyado en sus muletas. Así que me conoció, me pidió que fuera inmediatamente a su casa a avisar a la familia que no volvería hasta tarde, que no temieran, etcétera. "Pero no puedo salir, Horacio, no me dejan". La verdad era que había trabajado tanto por llegar a mi punto de observación y esperaba que en aquel patio tuvieran lugar cosas tan memorables, que lanzaba ese pretexto, harto plausible, para quedarme allí. "Un estudiante a quien no dejan salir, ipobrecito! -Entonces ustedes ya no saben escaparse?" Yo habría podido contestar que lo hacía con una frecuencia

14 Los «cocidos» eran quienes proponían que la Ciudad de Buenos Aires fuera convertida en la Capital Federal del país y fuera separada de la provincia de Buenos Aires, y los «crudos» los que se oponían a eso. 
que me ponía a cubierto de semejante reproche, pero preferí la acción y desaparecí. Me escapé con éxito, corrí a casa de Horacio, tranquilicé a la familia, volví al Colegio y, jadeante, extenuado, ocupé nuevamente mi sitio de observación, de donde di cuenta a Horacio de mi comisión." 15 .

La historia personal, la historia familiar y la historia nacional se tejen conjuntamente; la disputa entre porteños y provincianos se da tanto puertas adentro como puertas afuera, los edificios se interconectan, y las estrategias del estudiante sirven a las causas políticas. Metafóricamente, al espacio donde se decide el futuro del país no se llega por la calle sino por el colegio. El estudiante devino político.

Otro elemento típico de este tipo de obras es la presentación de los profesores en forma arquetípica, lo que favorece los procesos de constitución subjetiva mediante experiencias de identificación o de rechazo. En aquellos años, la condición de profesor de escuela media era muy prestigiosa y conformaba una especie de aristocracia. Hombres varones blancos en su totalidad, provenían casi exclusivamente de sectores socialmente acomodados. Algunos tenían algún título universitario profesional -lo que se consideraba habilitante por tal para el ejercicio de la docencia-, otros pocos eran clérigos, y un tercer grupo lo constituían laicos autodidactas reconocidos. Todos representantes de la alta cultura, sus descripciones enfatizan características como el «buen gusto», la «sobriedad» o la erudición. En el caso de Cané, el caso paradigmático es el francés Amadeo Jacques, republicano exiliado en Argentina, al que opone al clerical Padre Agüero y al español José María Torres. Así describe a su profesor admirado:

"Jacques llegaba indefectiblemente al Colegio a las nueve de la mañana; averiguaba si había faltado algún profesor, y en caso afirmativo, iba a la clase, preguntaba en qué punto del programa nos encontrábamos, pasaba la mano por su vasta frente como para refrescar la memoria, y en seguida, sin vacilación, con un método admirable, nos daba una explicación de química, de fí-

15 Miguel Cané, Juvenilia y otras páginas argentinas (Buenos. Aires: Espasa-Calpe, 1952). 
sica, de matemáticas en todas sus divisiones, aritmética, álgebra, geometría descriptiva o analítica, retórica, historia, literatura, ¡hasta latín! (...).

Debe estar fija en la memoria de mis compañeros aquella admirable conferencia de $\mathrm{M}$. Jacques sobre la composición del aire atmosférico. Hablaba hacía una hora, y ffenómeno inaudito en los fastos del Colegio!, sonar la campana de salida, uno de los alumnos se dirigió arrastrándose hasta la puerta, la cerró para que no entrara el sonido, y por medio de esta estratagema, ayudada por la preocupación de Jacques, tuvimos media hora más de clase. Había venido de buen humor ese día, y su palabra salía fácil, elegante y luminosa.

En ciertos momentos se olvidaba, y nos hablaba en francés, que todos entendíamos entonces. ¡Qué pintura inimitable de ese maravilloso fenómeno de la vegetación, de aquellas plantas con corazón de madre, absorbiendo el letal carbono de la atmósfera, y esparciendo a raudales el oxígeno, la esencia de la vida! ¡Cómo nos hablaba de la bajeza miserable del hombre que pisotea una planta, o abate un árbol para coger un fruto! ¡Aun suena en mis oídos su palabra, y, al recordarla, aún se apodera de mi alma aquella emoción nueva e inexplicable entonces para mí! (...)

Adorábamos a Jacques a pesar de su carácter; jamás faltábamos a sus clases, y nuestro orgullo mayor, que ha persistido hasta hoy, es llamarnos sus discípulos. A más, su historia, conocida por todos nosotros y pintorescamente exagerada, nos hacía ver en él, no sólo un mártir de la libertad, como lo fue en efecto, sino un hombre que había luchado cuerpo a cuerpo con Napoleón, nombre simbólico de la tiranía"16.

En síntesis, Juvenilia da cuenta de la construcción cultural de una nueva élite nacional en la segunda mitad del siglo XIX que se proponía insertar a

16 Miguel Cané, Juvenilia y otras páginas argentinas. 
la Argentina en el mundo occidental y capitalista, eliminando de su historia toda marca originaria y colonial previa. Para tal, era necesario acelerar el dominio de Buenos Aires sobre el interior y consagrar a la cultura francesa como símbolo de distinción. Los hechos relatados en esa obra se erigen como una de sus pruebas más contundentes.

Al cumplirse los cien años de la fundación del Colegio Nacional de Buenos Aires, Florencio Escardó ${ }^{17}$-destacado médico egresado de esa institución-, publicó su estudiantina. Escrita en la década de 1960, la obra habilita temas contemporáneos no presentes en la Juvenilia de Cané, tales como las diferencias de género -llama a un capítulo «el androceo»- y la iniciación sexual de los adolescentes. En la introducción, el autor aclara que no pretende reconstruir exactamente seres o acontecimientos sino el modo como los vivió una «generación de adolescentes», la que cursó sus estudios hacia finales de la década de 1910 -egresó en 1922-, y busca dar cuenta de las distintas modernizaciones que por entonces se sucedían en Argentina, entre las que se encuentra la consolidación de una incipiente clase media ${ }^{18}$.

Esos cambios están representados en la inauguración del nuevo edificio, «la casa nueva» del título de la obra, que trocó campanas por timbres, terminó con los restos de la arquitectura colonial previa, erigió un edificio de aspecto francés, y permitió el lento ingreso de una población masculina hija de la inmigración llegada a Argentina en las décadas previas. Los apellidos patricios protagonistas de la obra de Cané son trocados por nuevos de esos orígenes.

Por ejemplo, cuenta de uno de sus compañeros:

"Había en la división dos hermanos [...] Una tarde, paseando por el barrio de San Telmo, encontré al mayor cargando una

17 Florencio Escardó (1904-1992), destacado pediatra y sanitarista argentino. Ocupó el cargo de decano de la Facultad de Medicina y vicerrector de la Universidad de Buenos Aires. Su obra renovó la pediatría acercándola a los planteos de la medicina social y del psicoanálisis. Fue escritor y miembro de la vanguardia modernizadora argentina de las décadas de 1960 a 1970.

18 Al respecto véase Ezequiel Adamosky, Historia de la clase media argentina. Apogeo y decadencia de una ilusión, 1919-2003 (Buenos Aires: Planeta, 2009). 
canasta de almacén tan llena de mercaderías que apenas podía transportarla. Lo acompañé casa por casa a hacer el reparto, terminado el cual fuimos al almacén donde hallamos al menos que había concluido el suyo. Y de ahí fuimos a su casa. Vivían en la primera habitación de luna casa de inquilinato en la calle Balcarce con su madre, una española viuda que trabajaba su oficio de planchadora; Los muchachos con su reparto (que tenía como única retribución las propinas) lo ayudaban y se ayudaban para estudiar y para mantener as un hermano menor que cursaba la escuela primaria"19.

Como en su antecesor, el contexto se inscribe en la trama de la obra: aquí la Primera Guerra Mundial ocupa el lugar que el enfrentamiento entre «crudos y cocidos» en Juvenilia, y se proyecta en hechos posteriores como el peronismo y la Segunda Guerra Mundial. Al respecto, Escardó sostiene que:

"Llegó la guerra con sus terribles realidades morales y ya no nos fue tan fácil hablar de recuerdos. Algunos de aquellos compañeros que conocíamos tiernos muchachos de doce años, [...], con quienes habíamos compartido el banco, la billetera y las confidencias, se hicieron nazis y antisemitas. Era para no creerlo, pensándolo bien, su Intimo modo de ser, su apellido, sus tradiciones de familias debieron hacérnoslo pensar." 20

El dispositivo de identificación con los docentes que señalamos en la obra de Cané está también presente en esta. Escardó rescata a aquellos que proponían un vínculo más mundano y menos libresco con los contenidos, del tipo que luego él usaría en su cátedra. Así recuerda a uno de sus profesores de geografía:

“Don Samuel Donovan dictaba geografía de Europa. Asia y Áfri-

19 Florencio Escardó, La casa nueva. Evocaciones del Colegio Nacional de Buenos Aires (Buenos Aires: Campano, 1963).

20 Florencio Escardó, La casa nueva. 
ca; detrás de sus anteojos gruesos como peceras se movían agudos y velocísimos sus ojos celestes de esgrimista eximio; un tic inagotable lo hacía estirar con las manos flexionadas los puños almidonados que emergían de sus mangas. Nos enseñó el desprecio por los textos manidos y convencionales que matan el estudiante la imaginación y el libre examen. Cuando algún muchacho lo apremiaba desde la premisa de que sólo se podía aprender la materia guiado por un texto, le espetaba entre impaciente y burlón:

-Mire el mapa, lea "La Nación".

Y su respuesta tenía la misma trascendencia universal de aquella de Sydenham a Richard Blackmore: "Lea el Quijote". Si el muchacho se encocoraba, sin traición alguna don Samuel lo invitaba a dirimir diferencias en la pedana del Jockey Club, en cualquiera de las formas de esgrima desde el palo, el sable o el florete; ciando el mozo del fondo en su desconcierto no sabía qué hacer lo enviaba a comprar el diario y sobre cualquier telegrama comenzaba a tejer la visión geográfica de la ciudad nombrada con sus gentes, con su historia, con sus leyendas, con sus monumentos, con sus vinos o sus tejidos, dejándonos tan embobados que el día en que por obra de un gesto brioso el puño desprendido de la manga saltó sobre nuestras cabezas, nadie del auditorio se agachó a recogerlo, absortos como estábamos en sus descripciones; al final de la hora se marchó sin él y nunca volvió a buscarlo. Quedó en nuestro poder como un trofeo. Del mismo modo nos enseñó la triste utilidad del dato numeral por sí mismo; entrando en La clase se dirigía a conjunto preguntando del golpe:

- ¿Quién conoce la altura del Monte Blanco?

-Nunca faltaba el erudito que respondiera:

-4810 metros.

Y él:

-Usted no sabe nada, 4810 metros con veinticinco centímetros. Y salía del aula haciendo gestos de desilusión, para volver al rato a gozar de nuestro desconcierto y mirando de cerca al informado a través de las peceras le decía:

-No aprenda macanas, amigo, sepa que un monte muy alto tie- 
ne alrededor de 5000 metros y que el más alto está en el Tibet, que luego viene el Tupungato o cualquier otro; pero que todos son muy altos; están cubiertos de nieve y nadie vive en ellos, entonces, ¿Qué le importan los metros? Hábleme más bien de las mesetas, que es allí dónde viven las gentes.

Creo que don Samuel no dio nunca una lección formal; entraba y salía del aula cuando le venía la gana y nos tenía en vilo. Al final del curso habíamos adquirido, junto con un montón de nociones vividas, un profundo desprecio por los Boero y por toda la ralea de escribidores de textos" 21 .

El texto de Escardó da cuenta del desplazamiento del lugar de la enseñanza media en la Argentina en el período de entre guerras. Más abierta y tolerante, es una prueba más de su proceso de modernización periférica ${ }^{22}$ que de todas maneras no logra desprenderse de sus marcas de distinción culturales heredadas - por ejemplo, no hay en toda la obra una sola mención a las tradiciones americanas-, y adelanta futuros conflictos a desatarse en décadas posteriores.

En ambos casos -Cané y Escardó-, las biografías posteriores de los autores permiten encontrar fuertes elementos de identificación con los docentes presentados. En Cané, miembro de la oligarquía europeizante latinoamericana de fines del siglo XIX, se destaca la admiración por el enciclopedismo y el afrancesamiento, la constitución de una élite letrada sobre estas bases, y su identificación con la causa republicana. En Escardó, representante de las clases medias en ascenso del siglo XX que abrazaron causas progresistas, se remarca el desprecio por el saber memorístico, erudito y estructurado junto con la valoración del saber "de la vida", el rescate de lo mundano y del habitus del "bon vivant”. En los dos, la institución educativa es presentada como uno de los espacios centrales donde se desarrollaron las experiencias de vida que tallaron el destino y la identidad de sus autores. Los debates que estructuraron la construcción de la Nación -Buenos Aires y el Interior, parvenus y aristócratas, clericales y liberales, inmigrantes

21 Florencio Escardó, La casa nueva.

22 Beatríz Sarlo, Una modernidad periferica: Buenos Aires 1920 y 1930. (Buenos Aires: Nueva Visión, 1988). 
y nativos, hispanistas y «afrancesados», modernos y tradicionales- se presentan como ejes de la formación inicial de estos hombres destinados a ser parte de las élites culturales. Según sus voces, el país se reflejaba en el Colegio, y viceversa.

Con el tiempo, estas reglas de género se fueron debilitando, y permitieron la aparición de nuevos modelos. Por ejemplo, el relato se orientó al presente -su narrador ya no es alguien que recuerda su adolescencia, sino un adolescente que la vive en ese momento, o un joven que acaba de finalizarla-, y se retrae la nostalgia dando lugar a recordar principalmente situaciones molestas. El recuerdo melancólico deja paso a la reconstrucción de la experiencia subjetiva infantil y juvenil en el momento en que se produce. Las descripciones se humanizaron, y los profesores y alumnos se mostraron más reales y expuestos. El "deber ser" de las semblanzas previas da paso a presentaciones de sujetos más conflictivos y complejos, en las que no faltan tintes de denuncia y burla.

Veamos como ejemplo el caso de "Palermo" (2003), la novela breve en la que el Alejandro Caravario reconstruye su escuela secundaria en la década de 1980, durante el renacer democrático argentino en una escuela pública a la que concurre una clase media integrada. Así presenta a Liporace, su profesor de historia del último año:

"Tenía el cuello ladeado y una frente descomunal (...). (Recuerdo) cómo le llenábamos el saco de escupidas. El tipo recorría las hileras de pupitres, y cada estudiante que dejaba atrás se transformaba de inmediato en un artillero. Nos untábamos el dedo mayor con saliva, y, con un rápido y corto movimiento, lanzábamos el proyectil. A Pablo le llamaba la atención que, a pesar de que invariablemente se iba con el saco cubierto de manchas espumosas, Liporace nunca se enteró de nada. Al menos nunca dejó de pasearse por el aula con la retaguardia desprotegida. Nunca dejó de someterse a los ataques que, aunque repetidos -dice Pablo-, no perdían el encanto. Según el, un clima de fiesta sigilosa dominó cada clase de historia de quinto año. Hasta que, cuando faltaba 
un mes para terminar el curso, Liporace se quedó seco mientras esperaba el 111. El corazón" 23.

El proceso de identificación entre alumnos y profesores de los textos anteriores ha invertido la carga, y da lugar a una producción de identidades juveniles por oposición y no por identificación. Liporace, con su vida nimia y su muerte anodina, es presentado como "lo que no se debe ser" por las futuras generaciones. Movimientos similares se presentan en las memorias de los docentes, como se expondrá en el próximo apartado.

\subsection{Las memorias de docentes}

Por otra parte, las memorias de docentes -no necesariamente verídicasson también un tipo de escrito generado por la escuela para recuperar las experiencias de los sujetos. Son un género aún menor que las estudiantinas, seguramente por el lugar subordinado que los docentes han ocupado en la intelectualidad y la academia latinoamericana. A esto debe sumarse la condición de género -la mayoría de sus autores son mujeres-, lo cual dificultó aún más su jerarquización.

Movimientos similares a los identificados en la estudiantina a lo largo del siglo XX se ven aquí. Los primeros homenajes dejan paso a la asociación entre escuela y sensaciones desagradables, que se traduce del pasaje de la satisfacción sentida en la tarea a su padecimiento. Para el primer caso, vamos a referirnos a Jennie Howard, una de las maestras convocadas a Argentina por D. F. Sarmiento para dirigir Escuelas Normales a fines del siglo XIX, quien escribió en su idioma original sus memorias "En otros años y climas distantes". En ella hace la siguiente evaluación de su tarea:

"Las mismas maestras norteamericanas que habían organizado la Escuela y permanecido al frente de ella en los pasados años tomaron asiento en el palco oficial. Tan bañadas de lágrimas estaban los ojos al contemplar la conmovedora escena y al recibir las expresiones de gratitud de los afectuosos alumnos de los primeros tiempos y de los años intermedios, que apenas podían res- 
ponder a los que se agolparon luego a su alrededor para saludarlas con palabras cariñosas. Cuando, más tarde, se encontraron con el banquete, a la cabecera de las largas filas de mesas, pudieron abarcar con la mirada cada una de las promociones habidas desde la inauguración de la Escuela, veinticinco años ha, representadas por hombres y mujeres, muchos de ellos casados, con hijos y titulares de puestos dignos y útiles, llegados todos en aquel momento para colocar los flores de la gratitud y del recuerdo afectuoso a los pies de quienes habían tratado de guiarlos hacia los más altos ideales de la humanidad. Quedaron entonces borrados y olvidados para ellas los años de exilio de la tierra natal, los oscuros días de desalentadora labor y las ingratitudes ocasionales"24.

Con el tiempo, se fortaleció una mirada melancólica ante el "prestigio perdido" plagada de malestar y desasosiego. La literatura también da cuenta de esas posiciones permeadas por el discurso hegemónico que muestra un docente resignado, que ha perdido la autoridad y el reconocimiento de otrora, y que no se encuentra preparado para ejercer su tarea en determinadas condiciones concretas. Además del texto de Alejandro Caravario presentado en el apartado anterior, queremos referirnos acá a "Autorretrato" (1954), el anti poema del chileno Nicanor Parra, quien se desempeñó como profesor de matemática en una escuela media de su país. Presentamos aquí unos párrafos:

"Considerad, muchachos,

Este gabán de fraile mendicante:

Soy profesor en un liceo oscuro,

He perdido la voz haciendo clases.

(Después de todo o nada

Hago cuarenta horas semanales)

¿Qué les dice mi cara abofeteada?

¡Verdad que inspira lástima mirarme!

Y qué les sugieren estos zapatos de cura

Que envejecieron sin arte ni parte. 
En materia de ojos, a tres metros

No reconozco ni a mi propia madre

¿Qué me sucede? — ¡Nada!

Me los he arruinado haciendo clases

La mala luz, el sol,

La venenosa luna miserable.

Y todo ipara qué! (...)

Sin embargo, yo fui tal como ustedes, Joven, lleno de bellos ideales,

Soñé fundiendo el cobre

Y limando las caras del diamante:

Aquí me tienen hoy

Detrás de este mesón inconfortable

Embrutecido por el sonsonete

De las quinientas horas semanales"25.

Junto a estos movimientos de pérdida de reconocimiento, se comprueba que, en la segunda mitad del siglo XX muchos docentes se sumaron a las impugnaciones culturales contemporáneas que cuestionaban tanto las matrices tradicionales previas como la avanzada tecnocrática de entonces. Desde estas posiciones, jaquearon el autoritarismo y la vinculación cosificada con el saber enseñado, y propusieron nuevas prácticas que recuperan la palabra de los alumnos y relaciones más críticas y productivas con los conocimientos que tensaban la matriz selectiva fundacional ${ }^{26}$.

La literatura de la época da cuenta de esta situación, generalmente más en tono de denuncia que de propuesta. Hebe Uhart, en su cuento "Danielito y los filósofos" de 1983 relata una mesa de examen de filosofía en una escuela secundaria. Mientras toman el escrito, los profesores conversan acerca de sus vacaciones (uno a Europa, otro a Estados Unidos). En la mesa se presentaron tres alumnos. Dos aprueban. El tercero es Daniel, al que ya habían aplazado tres veces en la materia.

25 Nicanor Parra, Poemas y antipoemas (Santiago: Editorial Nascimento, 1954).

26 Hemos profundizado estos temas en Pablo Pineau y Alejandra Birgin, "Posiciones docentes del profesorado para la enseñanza secundaria en la Argentina: una mirada histórica para pensar el presente", Teoria e Prática da Educação, Vol. 18, No. 1 (2014): 47-61. 
"Buen - dijo la profesora Leneras porque no sos para eso. Estás aprobado.

Lo dijo con voz del más profundo desprecio.

Habitualmente, cuando se le dice a un chico que está aprobado, va corriendo a comunicarlo al comité de apoyo que lo espera afuera. Cosa curiosa, Danielito no se movía de ahí, estaba quieto, parado, mirando a uno y otro. (...)

Danielito dijo entonces algo inesperado, siempre con su voz monocorde:

- La verdad es que yo a los filósofos no los entiendo. Yo comprendo las cosas como a mí me parece, como yo pienso, de otra manera.

La profesora Lene no registró el pensamiento de Danielito porque estaba haciendo la planilla resumen. Sin escuchar, le dijo:

- Vaya, vaya a su casa. Su madre lo debe estar esperando atormentada. Hay que ver lo que es la angustia de una madre cuando su hijo da examen. Lo apruebo por su madre"27.

A lo largo del siglo, las evaluaciones de la tarea han invertido su valor, el festejo transmutó en lamento y denuncia, los dolores pesan más que las alegrías, y el paso del tiempo no trajo el reconocimiento sino la decadencia y la impugnación. Pero en todos los casos, la importancia de las experiencias laborales y profesionales es determinante: en el momento de la escritura, los autores son aquello que la tarea docente ha hecho con ellos. La construcción de la subjetividad es producto de la experiencia escolar, que por tal merece ser narrada por escrito.

\section{A Modo De CIERRE}

Los cambios actuales en las Ciencias Sociales han convocado a la historia de la educación respecto a cómo lograr reconstruir las experiencias concretas de sujetos activos, más allá de entenderlas como efecto de las intenciones de las políticas y acciones llevadas a cabo por las formas de poder. De esta manera, ha buscado separarse de abordajes previos que 
focalizaban en los efectos "civilizatorios" y "disciplinadores", en tanto y en cuanto prácticas de "normalización" y moldeamiento de sujetos que se presentan bastante poco agentes en dichos procesos.

El cruce entre los registros de la historia de la educación y la literatura permite desplegar el abanico de respuestas producidas. De acuerdo a esto, en este texto nos hemos propuesto indagar en ciertos puntos y ejemplos de la escritura de la experiencia escolar, en especial en algunos de los dispositivos narrativos que buscan comunicar las experiencias subjetivantes escolares a partir de la segunda mitad del siglo XIX. En ellos, la institución educativa es presentada como uno de los espacios centrales donde se desarrollaron las experiencias que tallaron el destino y la identidad de sus autores.

Al empezar, citábamos a Borges para intentar pensar qué es la experiencia. Tal vez sea bueno volver allí para terminar. Como sigue desarrollando el cuento de donde fue extractado ese párrafo, el intento de transmisión de la experiencia es por definición fallido: la experiencia solo le sucede a uno. Pero es en esta condición de imposibilidad donde alcanza su mayor nivel de productividad, ya que genera nuevas experiencias en el receptor. Si trasmitir es un acto imposible, la escritura es una de las mejores formas de explotar las potencialidades que dicha imposibilidad encierra. Se presenta así un campo muy fértil para futuras indagaciones en historia de la educación.

\section{Bibliografía}

\section{Fuentes primarias}

Borges, Jorge Luis. Obras completas. Buenos Aires: MC Editores, 1974. Cané, Miguel. Juvenilia y otras páginas argentinas. Buenos Aires: EspasaCalpe, 1952.

Caravario, Alejandro. Palermo. Buenos Aires: Paradiso Ediciones, 2003. Escardó, Florencio. La casa nueva. Evocaciones del Colegio Nacional de Buenos Aires. Buenos Aires: Campano, 1963.

Howard, Jennie. En otros años y climas distantes. Buenos Aires: Ed. Raigal, 1951.

Parra, Nicanor. Poemas y antipoemas. Santiago: Ed. Nascimento, 1954.

Uhart, Hebe. La luz de un nuevo día. Buenos Aires: CEAL, 1983.

Vargas Llosa, Mario. La ciudad y los perros. Barcelona: Seix Barral, 1963. 


\section{Fuentes secundarias}

Adamovsky, Ezequiel. Historia de la clase media argentina. Apogeo y decadencia de una ilusión, 1919-2003. Buenos Aires: Planeta, 2009.

Bajtin, Mijail. “La novela de educación”. En Estética de la creación verbal, editado por Mijail Bajtin. México: Siglo XXI, 1995, 200-247.

Escolano Benito, Agustín. "Reseña del libro: Stuart Walton, Humanidad. Una historia de las emociones". Historia y Memoria de la Educación, Vol. 2 (2015): 353-364.

Larrosa, Jorge. "Sobre la experiencia”. Educación y Pedagogía, vol. 18 (2006): 43-51.

Lenero Llaca, Martha Isabel. "Indicios literarios de la escuela: Aproximaciones a una poética de la memoria". En Lecturas in-apropiadas desde la historia, la educación y la cultura, editado por María Esther Aguirre Lora. México: Ediciones Díaz de Santos, 2013, 83-109.

Ludmer, Josefina. El cuerpo del delito. Un manual. Buenos Aires: Ed. Perfil, 1999.

Pineau, Pablo y Alejandra Birgin. "Posiciones docentes del profesorado para la enseñanza secundaria en la Argentina: una mirada histórica para pensar el presente". Teoria e Prática da Educação, Vol. 18 No. 1 (2015): 47-61.

Sarlo, Beatriz. Una modernidad periférica: Buenos Aires 1920 y 1930. Buenos Aires: Nueva Visión, 1988.

Trilla, Jaume. "Pedagogías narrativas". En La aborrecida escuela. Junto a una pedagogía de la felicidad y otras cosas, editado por Jaume Trilla. Barcelona: Laertes, 2002, 136-162.

Para citar este artículo: Pineau, Pablo. "Historia de la Educación y

178 Literatura. Miradas cruzadas para comprender la experiencia escolar", Vol. XIII No. 33 (Julio-Diciembre 2018): 151-176. DOI: http://dx.doi. org/10.15648/hc.33.2018.7 